\title{
Fit für die Führung
}

\author{
Spagat zwischen Team und Klinik - Pflegeleitungen stehen unter starkem Druck - \\ von oben und von unten. Wie sie diese Situation meistern, hat eine Studie untersucht. \\ Ein überraschendes Ergebnis: Mehr als jede zehnte Führungskraft feiert auch mal krank, \\ um sich zu erholen.
}

$\nabla$ Immer weniger Pflegepersonal, immer mehr Patienten, immer größerer Druck- so lässt sich die Situation von Schwestern und Krankenpflegern in deutschen Kliniken zusammenfassen. In den zehn Jahren zwischen 1995 und 2005 stieg die Belastungszahl des Pflegedienstes nach Fällen von 48,4 Patienten auf 55,8, berichtet das Statistische Bundesamt. Das entspricht einem Plus von $15,3 \%$.

Die steigende Belastung macht vor den Führungskräften in der Pflege nicht Halt. Im Gegenteil. Auch ihr Berufsalltag hat sich verdichtet, sie müssen sich stärker als früher darum kümmern, dass ihre Mitarbeiter dem Arbeitsdruck standhalten können und sind selbst durch ihre Sandwich-Position sehr belastet. Es schafft Stress, ,einerseits Arbeitgeberfunktion zu

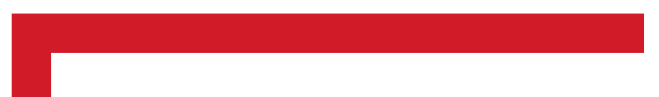 \\ - Tipps und Stresstest}

Der Bericht „Fit bleiben in der Führung - Ideen, Impulse, Instrumente" ist auf der website des DBfK abrufbar unter: www.dbfk.de

Einen Stresstest und Tipps, wie sich Belastun-

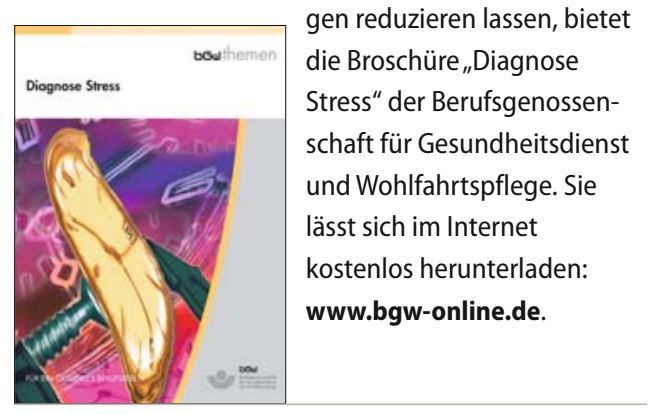

haben, führen und Vorbild sein zu müssen, in dieser Funktion auch häufig unangenehme Botschaften zu überbringen, andererseits die berechtigten Interessen des Teams zu berücksichtigen und wahrzunehmen und darüber hinaus als Mitarbeitende auch selbst unmittelbar Mitglied des Teams zu sein“, resümiert Johanna Knüppel vom Deutschen Berufsverband für Pflegeberufe (DBfK) in ihrem Bericht über die Fitness-Strategien von Führungskräften in der Pflege, den der Verband gerade veröffentlicht hat.

Gut 200 Pflegeleitungen hat der DBfK nach ihren aktuellen Anforderungen im Job und persönlichen Bewältigungsmustern befragt. Ergebnis: Knapp 37\% der Führungskräfte fühlten sich aktuell sehr belastet, über $7 \%$ sogar „extrem belastet“. Dies galt vor allem für Pflegemanager mit berufsbedingten Erkrankungen. Das war immerhin ein Fünftel der Befragten. 65,2\% litten demnach an Muskel- und Skeletterkrankungen, 21,7\% an psychischen und psychosomatischen Krankheiten.

\section{Wichtiges soziales Netz}

Überraschend fiel die Analyse der Gegenstrategien aus: Als wichtigste Ressource nannten die Befragten Familie und Freunde. $98 \%$ gaben an, dass ihr soziales Netz mehrmals monatlich zum Tragen kommt und sie entlastet. Über 35\% nutzten aber auch mindestens einmal im Monat professionelle Angebote zur Unterstützung wie Coaching, Supervision oder kollegiale Beratung. Auf fachliche Fortbildung zur Stressreduktion setzten jedoch wenige. Nur etwa $16 \%$ bildeten sich einmal im Jahr weiter. „Eine kritische Größe“, urteilt der DBfK.

Sport als Ausgleich trieben $84 \%$ und $53 \%$ setzten mehrmals im Monat Entspannungstechniken ein. Genauso populär war der „stille Rückzug“. Er ist „offenbar eine gern und sehr häufig genutzte Möglichkeit, sich Erholung von den Belastungen des Berufs zu verschaffen“, folgert Knüppel.

\section{Reif für eine Auszeit}

Eine längere Auszeit ohne Bezahlung, „Sabbatical“ genannt, spielt in der Pflege offensichtlich keine Rolle. 98,5\% gaben an, dies nie genutzt zu haben. Als einen Grund vermutet Knüppel, dass die Gehälter von Pflegemanagern zu niedrig sind, um etwas für einen solchen unbezahlten Urlaub anzusparen. Viele Führungskräfte in der Pflege sind aber reif für eine Auszeit. Und nehmen sich diese auch: So gaben mehr als $11 \%$ der Befragten $\mathrm{zu}$, sich durchschnittlich einmal im Jahr krank zu melden, um sich dem Druck am Arbeitsplatz für einige Tage zu entziehen.

Der DBfK rät Führungskräften zu einem individuellen Anti-Stress-Programm. Dazu müssten sie lernen, Symptome zu erkennen und ihnen vorzubeugen, indem sie Belastungen wahrnehmen. Ziel sei es, eine Balance zwischen Arbeit, Familie und Zeit für sich selbst zu finden. Knüppel: „Viele Manager glauben, wenn sie viel zu tun haben, sind sie wichtig. Aber nur wer verantwortungsvoll mit sich selbst umgeht, hat auch Führungsqualitäten.“

- Martina Janning 